Article

\title{
Insulin-Like Growth Factor-II and Ischemic Stroke- A Prospective Observational Study
}

\author{
Daniel Åberg 1,2,*(1), N. David Åberg 1,2,3@ , Katarina Jood 2,4, Petra Redfors ${ }^{2,4}$, Christian Blomstrand 2,3,4(0), \\ Jörgen Isgaard ${ }^{1,2}$, Christina Jern ${ }^{4,5}$ and Johan Svensson ${ }^{1,2}$ \\ 1 Institute of Medicine, Department of Internal Medicine and Clinical Nutrition, The Sahlgrenska Academy, \\ University of Gothenburg, 40530 Gothenburg, Sweden; david.aberg@medic.gu.se (N.D. $\AA$. ); \\ jorgen.isgaard@medic.gu.se (J.I.); johan.svensson@medic.gu.se (J.S.) \\ 2 Region Västra Götaland, Sahlgrenska University Hospital, 41345 Gothenburg, Sweden; \\ katarina.jood@neuro.gu.se (K.J.); petra.redfors@vgregion.se (P.R.); christian.blomstrand@neuro.gu.se (C.B.) \\ 3 Institute of Neuroscience and Physiology, Center of Brain Repair and Rehabilitation, \\ The Sahlgrenska Academy, University of Gothenburg, 40530 Gothenburg, Sweden \\ 4 Institute of Neuroscience and Physiology, Department of Clinical Neuroscience, The Sahlgrenska Academy, \\ University of Gothenburg, 40530 Gothenburg, Sweden; christina.jern@neuro.gu.se \\ 5 Institute of Biomedicine, Department of Laboratory Medicine, The Sahlgrenska Academy, \\ University of Gothenburg, 40530 Gothenburg, Sweden \\ * Correspondence: daniel.aberg@medic.gu.se; Tel.: +46-313-428-423; Fax: +46-318-253-30
}

check for updates

Citation: Åberg, D.; Åberg, N.D.; Jood, K.; Redfors, P.; Blomstrand, C.; Isgaard, J.; Jern, C.; Svensson, J. Insulin-Like Growth Factor-II and Ischemic Stroke-A Prospective Observational Study. Life 2021, 11, 499. https://doi.org/10.3390/ life11060499

Academic Editors: Elsa Azevedo and Pedro Castro

Received: 5 March 2021

Accepted: 26 May 2021

Published: 29 May 2021

Publisher's Note: MDPI stays neutral with regard to jurisdictional claims in published maps and institutional affiliations.

Copyright: (c) 2021 by the authors. Licensee MDPI, Basel, Switzerland. This article is an open access article distributed under the terms and conditions of the Creative Commons Attribution (CC BY) license (https:// creativecommons.org/licenses/by/ $4.0 /)$.
Abstract: Insulin-like growth factor-II (IGF-II) regulates prenatal brain development, but the role in adult brain function and injury is unclear. Here, we determined whether serum levels of IGF-II (s-IGF-II) are associated with mortality and functional outcome after ischemic stroke (IS). The study population comprised ischemic stroke cases $(n=492)$ and controls $(n=514)$ from the Sahlgrenska Academy Study on Ischemic Stroke (SAHLSIS). Functional outcome was evaluated after 3 months and 2 years using the modified Rankin Scale (mRS), and additionally, survival was followed at a minimum of 7 years or until death. S-IGF-II levels were higher in IS cases both in the acute phase and at 3-month follow-up compared to controls ( $p<0.05$ and $p<0.01$, respectively). The lowest quintile of acute s-IGF-II was, compared to the four higher quintiles, associated with an increased risk of poststroke mortality (median follow-up 10.6 years, crude hazard ratio (HR) 2.34, 95\% confidence interval (CI) 1.56-3.49, and fully adjusted HR 1.64, 95\% CI 1.02-2.61). In contrast, crude associations with poor functional outcome (mRS 3-6) lost significance after full adjustment for covariates. In conclusion, s-IGF-II was higher in IS cases than in controls, and low acute s-IGF-II was an independent risk marker of increased mortality.

Keywords: insulin-like growth factor-II; ischemic stroke; functional outcome; modified Rankin Scale; mortality; National Institutes of Health Stroke Scale (NIHSS)

\section{Introduction}

Insulin-like growth factor-I (IGF-I) and IGF-II promote growth, metabolism, regeneration, and repair mechanisms in the peripheral tissues and in the central nervous system (CNS) [1,2]. IGF-I and IGF-II are mainly produced in the liver [3], but there is also production in other tissues including the CNS, most prominently in neurons [4,5]. Furthermore, IGF-I as well as IGF-II can pass through the blood-brain barrier [6], and both the IGF-I receptor (IGF1R) and the IGF-II receptor (IGF2R) are widely distributed in the brain, predominantly in the brain endothelium and in the choroid plexus $[7,8]$. The IGF2R, which is also a mannose 6-phosphate receptor, has a high affinity for IGF-II, and a low affinity for IGF-I $[7,8]$. The IGF2R targets acid hydrolases and IGF-II to lysosomes [8,9]. However, the IGF2R can also recruit $G$ proteins, thereby activating a cascade involving protein kinase $C$ (PKC) and phospholipase $C[8,10]$, which is distinct from that of the typical IGF-I signaling. 
IGF-II is important for cell genesis and prenatal growth. In children, IGF-II mutations were associated with retarded longitudinal growth as well as speech and motor delay despite a compensatory increase in serum IGF-I [11]. In adulthood, the role of IGF-II is not clear, although it is several-fold more abundant than IGF-I in serum, and the level of s-IGF-II is less dependent on growth hormone (GH) than that of IGF-I $[1,3,12]$. However, experimental data support that IGF-II regulates CNS functions also in adult life. In rats, administration of IGF-II enhanced memory consolidation, although the effect was dependent on the exact timing, i.e., within a sensitive period, of IGF-II administration [13] IGF-II was also involved in the effects on memory consolidation exerted by SHARP1 and SHARP2, two transcription factors regulating sleep/wake homeostasis [14]. In addition, normalization of IGF-II in aged rats improved memory functions [15], and IGF-II treatment provided protection from oxidative damage both in the aging rat brain [16] and after glucocorticoid exposure $[17,18]$. Interestingly, IGF-II might also affect the life span. A mouse model mimicking the human Silver-Russell syndrome was characterized by undetectable Igf2 expression, fetal growth retardation, and perinatal lethality [19]. Human studies of the APAI polymorphism in the IGF2 gene have shown that the APAI A allele is associated with higher serum IGF-II (s-IGF-II) and less obesity $[16,20,21]$ as well as a prolonged life expectancy [22]. Finally, in Italian centenarians, there was an association in men between longevity and tyrosine hydroxylase-IGF2 haplotypes on the 11p15.5 chromosomal region [23].

IGF-II could also be involved in the recovery from stroke, possibly by modulating the immunoreactive response of glial cells [24]. Furthermore, IGF-II was expressed in activated macrophages around an ischemic event [25], and the IGF2R was upregulated in ischemic neocortical pyramid neurons after focal cerebral ischemia in young hypertensive male rats [26]. Additionally, it has been possible to modulate IGF-II activity as the small protein RNA-binding motif protein 3 (RBM3) promoted IGF-II expression and secretion in the subgranular zone of the adult rodent dentate gyrus, thereby providing neuroprotection and neurogenesis after hypoxic-ischemic brain injury [27]. One human nested case-control study showed lower IGF-II levels in subjects with a subsequent ischemic stroke during follow-up compared to controls, although without statistical significance [28]. Otherwise, little is known of the role of IGF-II in human brain diseases. Studies on Alzheimer's disease (AD) show conflicting results; serum IGF-II has been reported to be reduced [12], unchanged [29], or increased [30] in AD, whereas IGF-II in the cerebrospinal fluid (CSF) has mostly been observed to be increased [12,29].

In summary, recent data suggest that IGF-II is associated with life expectancy and CNS functions, and some experimental findings indicate protective effects of IGF-II in the ischemic brain. However, there is little knowledge of IGF-II levels in human ischemic stroke (IS). We therefore analyzed s-IGF-II in the Sahlgrenska Academy Study on Ischemic Stroke (SAHLSIS) and investigated associations with mortality and long-term functional outcome after IS.

\section{Materials and Methods}

\subsection{Study Population}

The design of SAHLSIS has previously been reported in detail [31,32]. Briefly, 600 patients with first-ever or recurrent acute IS before the age of 70 years were consecutively recruited at four stroke units in western Sweden. The controls were without a clinically known cardiovascular disease $(\mathrm{N}=600)$ and randomly selected either from a populationbased health survey or the Swedish Population Register, to match the patients in terms of age ( $<1$ year), sex, and area of residence. This study was approved by the Ethics Committee of the University of Gothenburg. All participants or their next of kin provided written informed consent. 


\subsection{Vascular Risk Factors, Stroke Severity, and Subtypes}

Body mass index (BMI), hypertension, diabetes mellitus, and smoking were registered as described previously [31,32]. Initial stroke severity was assessed in the acute phase (the maximum score during days 0-10) and after 3 months using the Scandinavian Stroke Scale (SSS). The SSS is similar to the more frequently used National Institutes of Health Stroke Scale (NIHSS) [33], although the scales are inverse (i.e., higher values indicate mild stroke in SSS). Therefore, the SSS scores were recalculated to NIHSS scores using the validated algorithm NIHSS $=25.68-0.43 \times$ SSS [34]. Etiological subtypes were classified using the Trial of Org 10172 in Acute Stroke Treatment (TOAST) criteria [35] into the subtypes large vessel disease (LVD), small vessel disease (SVD), cardioembolic (CE) stroke, cryptogenic stroke (when no cause was identified despite extensive evaluation), other determined cause of stroke, and undetermined stroke using a local specified protocol as described previously [31].

\subsection{Functional Outcome and Mortality}

Functional outcome was evaluated after 3 months and 2 years using the modified Rankin Scale (mRS). We dichotomized the mRS score for poor outcome (mRS 3-6), indicating death or functional dependence, vs. good outcome (mRS 0-2), indicating functional independence. We used the unique 10-digit Swedish person identity number to identify all patients who had died from the Swedish Population Register (Folkbokföringen). The follow-up time was a minimum of 7 years or until death.

\subsection{Blood Sampling and Biochemical Analysis}

Venous blood samples were collected in the acute phase (median 4 days, range 1-10 days after the index stroke) and at the 3-month follow-up (median 101, range 85-125 days) in IS cases and once in controls. Blood sampling was performed between 08:30 and 10:30 a.m. after an overnight fast of $>8 \mathrm{~h}$. Serum was isolated within $2 \mathrm{~h}$ by centrifugation at $2000 \times g$ at $4{ }^{\circ} \mathrm{C}$ for $20 \mathrm{~min}$ and stored at $-80^{\circ} \mathrm{C}$ for before assay. S-IGF-II levels were measured by an enzyme linked immunosorbent assay (ELISA) using a commercial kit from Mediagnost, Reutlingen, Germany. The inter-assay coefficient of variation was $7.0 \%$, and the intra-assay coefficient of variation was $4.2 \%$. All blood and plasma concentrations of glucose and lowdensity lipoprotein cholesterol (hereafter LDL) were analyzed using standardized methods at the Department of Clinical Chemistry at the Sahlgrenska University Hospital. HOMAIR was calculated as fasting insulin $($ microU/L) $\times$ fasting glucose $(\mathrm{nmol} / \mathrm{L}) / 22.5$ [36] High-sensitivity CRP (hs-CRP) was analyzed in serum by a solid-phase chemiluminescent immunometric assay on Immulite 2000 (Diagnostic Products Corp, Los Angeles, CA, USA) with the manufacturer's reagents as directed [37].

\subsection{Statistical Evaluation}

The statistical analyses were performed using SPSS version 26.0 (IBM Corp., Armonk, NY, USA). Serum IGF-II was normally distributed according to the Kolmogorov-Smirnov test. Between-group differences were analyzed using ANOVA followed by Tukey's HSD post hoc test for continuous variables and using chi-square tests for categorical variables. Correlation coefficients were calculated using Pearson correlation analysis.

Kaplan-Meier survival curves were constructed to exhibit survival rates in individual quintiles of s-IGF-II as well as in the lowest quintile of s-IGF-II compared to the merged group of the four higher s-IGF-II quintiles. In the following regression analyses, we compared the lowest quintile of s-IGF-II with that in the merged group of the four higher s-IGF-II quintiles. This is in line with earlier studies of biological and endocrine biomarkers and the IGF family, which implicate an inverse nonlinear excess risk in deficient subjects and that there may be a threshold level of IGF-II $[28,38,39]$. We evaluated whether s-IGFII was associated with all-cause mortality (henceforth mortality) by calculating hazard ratios (HRs) and 95\% confidence intervals (CIs) using Cox proportional hazards regression analysis comparing the lowest quintile of s-IGF-II with that in the merged group of the four 
higher s-IGF-II quintiles. Furthermore, to evaluate whether s-IGF-II was associated with poor functional outcome (mRS 3-6), using binary logistic regression analysis, we calculated odds ratios (ORs) and 95\% CIs comparing the risk in the lowest quintile of s-IGF-II with that in the merged group of the four higher s-IGF-II quintiles.

To examine the independent effect of IGF-II on mortality and functional outcome, in line with that performed previously [32,40], adjustments were made for covariates related to stroke severity and well-known metabolic and cardiovascular risk factors. In these analyses, as LDL had the most missing values, imputation was used to replace the missing values with the mean LDL value. A two-tailed $p$-value of $<0.05$ was considered statistically significant.

\subsection{Ethics Approval and Consent to Participate}

This study was conducted in accordance with the 1964 Helsinki Declaration and its later amendments or comparable ethical standards. Participants or next of kin provided written informed consent. This study was approved by the Ethics Committee of the University of Gothenburg (Ö469-99 and T553-03). The Ethics Committee of the University of Gothenburg is responsible for ethical applications from the entire region of western Sweden, covering all four hospitals in the study.

\section{Results}

\subsection{Baseline Characteristics}

In the present study, we included 492 patients and 514 controls that had successful analysis of IGF-II, with clinical characteristics provided in Table 1. The mean age at inclusion was 57.2 years, and $64 \%$ were men. As previously reported [31,32,40], IS cases had more hypertension, diabetes mellitus, smoking, and higher HOMA-IR as well as hsCRP than matched healthy controls. However, LDL levels and BMI did not differ significantly. Although serum IGF-II was higher in IS cases both in the acute phase and after 3 months compared to controls ( $p<0.05$ and $p<0.01$, respectively), there was no significant poststroke difference between the acute and 3-month s-IGF-II levels. With regard to IS subtypes, both acutely and after 3 months, s-IGF-II was significantly higher in cryptogenic stroke $(7.3 \%)$, and lower in cardioembolic stroke (6.2\%), as compared with the controls (Table 1).

Table 1. Baseline characteristics in ischemic stroke (IS) patients and healthy controls as well as in IS subtypes.

\begin{tabular}{|c|c|c|c|c|c|c|}
\hline & Controls $(n=514)$ & Patients $(n=492)$ & $\begin{array}{c}\text { Large Vessel } \\
\text { Disease }(n=54)\end{array}$ & $\begin{array}{c}\text { Small Vessel } \\
\text { Disease }(\mathrm{n}=106)\end{array}$ & \multicolumn{2}{|c|}{$\begin{array}{l}\text { Cardioembolic Stroke }(\mathrm{n}=81) \\
\text { Cryptogenic Stroke }(\mathrm{n}=131)\end{array}$} \\
\hline Age (years) & $57.2 \pm 0.44$ & $57.2 \pm 0.44$ & $58.5 \pm 1.00$ & $59.3 \pm 0.66^{*}$ & $58.9 \pm 1.14$ & $54.1 \pm 0.94^{* *}$ \\
\hline Male sex, n (\%) & $329(64)$ & $315(64)$ & $39(72)$ & $66(62)$ & $66(68)$ & $77(59)$ \\
\hline Hypertension, n (\%) & 199 (39) & $299(62) * * *$ & $30(60) * * *$ & $78(74) * * *$ & $44(56) * *$ & $73(57) * * *$ \\
\hline Diabetes mellitus, n (\%) & $30(6)$ & $94(19)^{* * *}$ & $19(38)^{* * *}$ & $25(24) * * *$ & $15(19)^{* * *}$ & $17(13)^{* * *}$ \\
\hline Current smoker, $\mathrm{n}(\%)$ & $89(17)$ & $193(39)^{* * *}$ & $27(54)^{* * *}$ & $46(43) * * *$ & $29(37) * * *$ & $50(39)^{* * *}$ \\
\hline hsCRP (mg/L) & $3.06 \pm 0.26$ & $10.8 \pm 1.00^{* * *}$ & $12.1 \pm 2.51 * * *$ & $4.95 \pm 0.66^{* *}$ & $16.7 \pm 3.18^{* * *}$ & $7.98 \pm 1.52 * *$ \\
\hline Imputed LDL (ng/nL) & $3.33 \pm 0.04$ & $3.35 \pm 0.04$ & $3.54 \pm 0.15$ & $3.48 \pm 0.08$ & $3.08 \pm 0.11^{*}$ & $3.32 \pm 0.07$ \\
\hline HOMA-IR & $2.13 \pm 0.12$ & $4.80 \pm 0.25^{* * *}$ & $6.14 \pm 0.88^{* * *}$ & $5.06 \pm 0.71^{* * *}$ & $4.59 \pm 0.53^{* * *}$ & $3.78 \pm 0.27^{* * *}$ \\
\hline BMI $\left(\mathrm{kg} / \mathrm{m}^{2}\right)$ & $26.5 \pm 0.18$ & $26.7 \pm 0.20$ & $26.8 \pm 0.65$ & $27.0 \pm 0.42$ & $26.8 \pm 0.51$ & $26.4 \pm 0.34$ \\
\hline NIHSS score baseline & NA & $5.32 \pm 0.25$ & $6.49 \pm 0.85$ & $3.32 \pm 0.26$ & $6.48 \pm 0.78$ & $5.24 \pm 0.48$ \\
\hline mRS score 3 months & NA & $1.79 \pm 0.05$ & $2.14 \pm 0.16$ & $1.35 \pm 0.10$ & $2.01 \pm 0.15$ & $1.73 \pm 0.10$ \\
\hline mRS score 2 years & NA & $1.88 \pm 0.06$ & $1.77 \pm 0.24$ & $1.49 \pm 0.11$ & $2.17 \pm 0.17$ & $1.68 \pm 0.10$ \\
\hline s-IGF-II acute $(\mathrm{ng} / \mathrm{mL})$ & $712.1 \pm 5.58$ & $734.7 \pm 7.08^{*}$ & $747.0 \pm 18.8$ & $734.6 \pm 13.7$ & $667.9 \pm 17.1^{* *}$ & $764.4 \pm 12.2^{* * *}$ \\
\hline $\begin{array}{l}\text { s-IGF-II } 3 \text { months } \\
\text { (ng/mL) }\end{array}$ & NA & $736.8 \pm 6.91^{* *}$ & $751.9 \pm 23.3$ & $739.5 \pm 14.8$ & $679.4 \pm 14.5^{*}$ & $748.4 \pm 11.0$ ** \\
\hline
\end{tabular}

Data are shown as means ( \pm SEM) or as number (n). Values are provided for controls, the total IS cohort, and the four major etiological IS subtypes. The remaining patients had either another determined cause $(n=37)$ or an undetermined cause $(n=83)$. Differences compared to the control group were examined using ANOVA for continuous variables and the $\chi 2$-test for categorical variables (sex, hypertension, diabetes, and smoking). Furthermore, for each of the stroke etiologies, the values are compared to controls. ns, not significant. LDL, low-density lipoprotein; BMI, body mass index; hsCRP, high-sensitivity C-reactive protein; HOMA-IR, homeostasis model assessment of insulin resistance. ${ }^{*} p<0.05,{ }^{* *} p<0.01,{ }^{* * *} p<0.001$.

Serum IGF-II was lower in older subjects as reflected by inverse correlations between age and s-IGF-II (acutely: $\mathrm{r}=-0.20, p<0.001$ (Figure 1A); after 3 months: $\mathrm{r}=-0.13$, $p<0.001$; and in controls: $\mathrm{r}=-0.10, p<0.001$ ). Moreover, acute but not 3-month s-IGF-II correlated inversely with NIHSS, i.e., stroke severity $(r=-0.10, p=0.03$ and $r=0.002$, 
$p=0.95$, respectively; not shown). Furthermore, acute s-IGF-II correlated negatively with hsCRP ( $\mathrm{r}=-0.24, p<0.001)$, and positively with LDL $(\mathrm{r}=0.14, p=0.002)$, but not with day of blood sampling $(\mathrm{r}=0.02, p=0.72)$, insulin resistance (HOMA-IR; $\mathrm{r}=-0.04, p=0.43$ ), or $\operatorname{BMI}(\mathrm{r}=-0.03, p=0.57)$.

$1 \mathrm{~A}$.

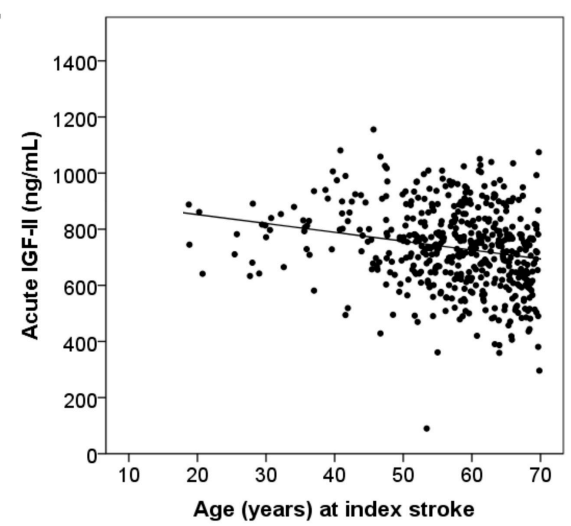

1B.

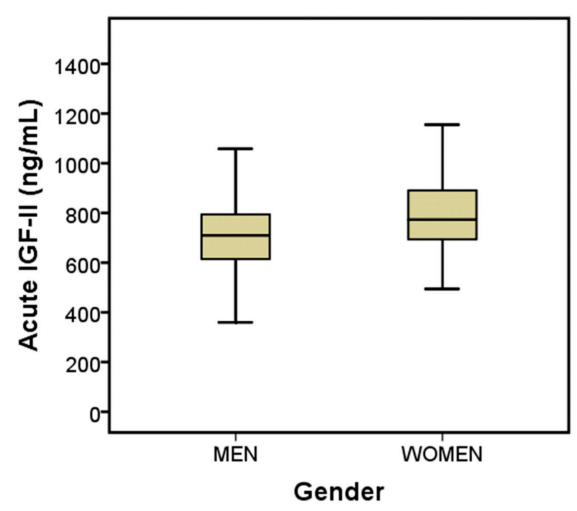

Figure 1. S-IGF-II and age and sex in the acute phase of ischemic stroke. (A) S-IGF-II levels in the acute phase were inversely correlated with age in the total stroke cohort $(n=492 ; r=-0.20, p<0.001)$. The equation for the relation is s-IGF-II $(\mathrm{ng} / \mathrm{mL})=916-[3.16 \times$ age (years)], valid through 18 to 70 years of age. (B) Boxplots of s-IGF-II in men $(n=315)$ and women $(n=177)$ in the acute phase after stroke. Values in the box plots are provided as medians (horizontal lines), 25-75th percentiles (boxes), and ranges (whiskers). Stroke men had lower acute s-IGF-II than stroke women $(p<0.001)$.

Women had higher values of s-IGF-II compared to men. S-IGF-II of women in the acute phase of stroke was $10.7 \%$ higher $(p<0.001$, Figure $1 \mathrm{~B})$ and $11.6 \%$ higher 3 months after stroke $(p<0.001)$, and $7.7 \%$ higher among the controls $(p<0.001)$.

\subsection{S-IGF-II and Risk of Mortality}

The follow-up time was a minimum of 7 years or until death (median 10.6, interquartile range 9.5-11.6 years). Kaplan-Meier survival curves showed an increased rate of poststroke mortality in the lowest quintile of acute s-IGF-II compared to that in the other quintiles (Figure 2A). In contrast, the mortality rate was approximately similar in quintiles 2-5 of acute s-IGF-II, providing the rationale for merging these (as described in more detail in the Methods section). Accordingly, when mortality was assessed as a comparison between quintile 1 vs. quintiles $2-5$, low acute s-IGF-II was still associated with increased mortality (log-rank test, $p<0.001$, Figure 2B). Furthermore, in Cox proportional hazards regression analyses using the merged four highest IGF-II quintiles as reference, low acute s-IGF-II was associated with increased mortality (quintile 1 vs. quintiles 2-5: crude HR 2.34, 95\% CI: 1.56-3.49, fully adjusted (model D): HR 1.64, 95\% CI: 1.02-2.61; Table 2). In contrast, s-IGF-II quintiles after 3 months were not associated with mortality (data not shown). 
2A.

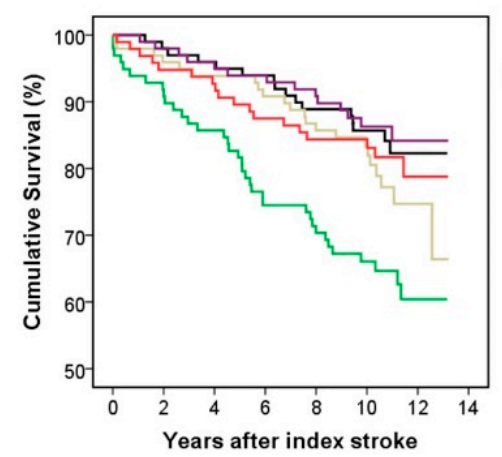

$\begin{array}{llcc}\text { No. at risk 490 } & \mathbf{4 5 2} & \mathbf{2 5 4} & \mathbf{3 7} \\ \text { Cumulative } 0 & \mathbf{3 6} & \mathbf{7 8} & 105\end{array}$ deaths
2B.

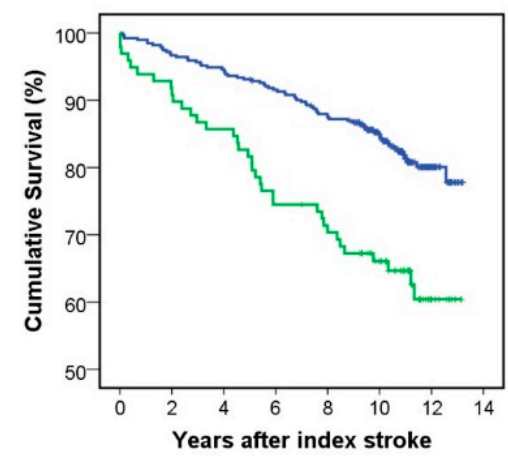

$\begin{array}{llcc}\begin{array}{l}\text { No. at risk 490 } \\ \text { Cumulative } 0\end{array} & 452 & 254 & 37 \\ \text { deaths } & 36 & 78 & 105\end{array}$

Figure 2. Low s-IGF-II in the acute phase of ischemic stroke (IS) is associated with increased risk of mortality. Kaplan-Meier survival curves for the risk of all-cause mortality are shown for (A) all individual quintiles of acute s-IGF-II in the total IS cohort, and (B) the lowest quintile of acute s-IGF-II (quintile 1) and the merged group of the four higher acute s-IGF-II quintiles (quintiles 2-5) in the total IS cohort. Vertical markers within the lines represent censored data. In (A), the individual quintiles of acute s-IGF-II are shown in the colors specified in the panel. In (B), quintile 1 of acute s-IGF-II is displayed as a green line and the merged quintiles $2-5$ of acute s-IGF-II as a blue line. Numbers at risk and cumulative mortality are presented at the index stroke and after 4, 8, and 12 years post-stroke. Panel A: log-rank tests: $p=0.001$ quintile 1 vs. quintile $2 ; p=0.025$ quintile 1 vs. quintile $3 ; p<0.001$ quintile 1 vs. quintile 4 ; and $p=0.06$ quintile 1 vs. quintile 5. Panel B: $\log$-rank test: $p<0.001$ quintile 1 vs. the merged quintiles $2-5$.

Table 2. Hazard ratios (HRs) and 95\% confidence intervals (CIs) for the risk of mortality in the lowest quintile of acute serum IGF-II compared to the four higher IGF-II quintiles in the total stroke population.

\begin{tabular}{cccc}
\hline Total Stroke Population & Acute Serum IGF-II Quintile 1 & Quintiles 2-5 & $p$-Value \\
\hline Deaths, n (\%) & $36(36.7 \%)$ & $70(17.9 \%)$ & $<0.001$ \\
Crude & $2.34(1.56-3.49)$ & 1.0 referent & 0.001 \\
Multivariate model A & $1.96(1.29-2.95)$ & 1.0 referent & 0.004 \\
Multivariate model B & $1.93(1.23-3.03)$ & 1.0 referent & 0.035 \\
Multivariate model C & $1.65(1.04-2.63)$ & 1.0 referent & 0.039 \\
Multivariate model D & $1.64(1.02-2.61)$ & 1.0 referent & \\
\hline
\end{tabular}

Hazard ratios were calculated using Cox proportional hazards regression. Data are shown as n (\%) and HR (95\% CI). Model A: adjustment for age and sex. Model B: age, sex, and cardiovascular risk factors (BMI, hypertension, LDL, smoking, and diabetes). Model C: age, sex, cardiovascular risk factors, and stroke severity. Model D: age, sex, cardiovascular risk factors, stroke severity, and hsCRP. LDL, low-density lipoprotein; BMI, body mass index; hsCRP, high-sensitivity C-reactive protein.

\subsection{Serum IGF-II and Functional Outcome}

In the total cohort $(n=490)$, binary logistic regression analyses showed that the lowest quintile of acute s-IGF-II was associated with increased risk of poor functional outcome (mRS 3-6) after 3 months (crude OR 2.30, 95\% CI 1.39-3.82) and 2 years (crude OR 1.93, 95\% CI 1.17-3.18). These ORs remained statistically significant with adjustments for age and sex, attenuated after adjustment for cardiovascular covariates, whereas the associations were not retained after adjustments for stroke severity and hsCRP (Table 3). 
Table 3. Odds ratios (ORs) and $95 \%$ confidence intervals (CIs) for the risk of poor functional outcome (mRS $\geq 3$ ) after 3 months and 2 years in the lowest quintile of acute serum IGF-II compared to the four higher IGF-II quintiles in the total stroke population.

\begin{tabular}{|c|c|c|c|c|}
\hline Total Stroke Population & Quintile 1 & Quintile 2-5 & $p$-Value & $\mathbf{n}$ \\
\hline \multicolumn{5}{|l|}{ 3-month mRS } \\
\hline Crude & $2.30(1.39-3.82)$ & 1.0 referent & 0.001 & 463 \\
\hline Multivariate model A & $2.24(1.33-3.79)$ & 1.0 referent & 0.002 & 463 \\
\hline Multivariate model B & $1.95(1.10-3.45)$ & 1.0 referent & 0.023 & 446 \\
\hline Multivariate model C & $0.99(0.46-2.13)$ & 1.0 referent & 0.98 & 446 \\
\hline Multivariate model D & $0.71(0.30-1.64)$ & 1.0 referent & 0.42 & 445 \\
\hline \multicolumn{5}{|l|}{ 2-year mRS } \\
\hline Crude & $1.93(1.17-3.18)$ & 1.0 referent & 0.010 & 485 \\
\hline Multivariate model A & $1.76(1.04-2.95)$ & 1.0 referent & 0.034 & 485 \\
\hline Multivariate model B & $1.59(0.90-2.80)$ & 1.0 referent & 0.11 & 463 \\
\hline Multivariate model C & $0.90(0.46-1.77)$ & 1.0 referent & 0.76 & 463 \\
\hline Multivariate model D & $0.79(0.39-1.58)$ & 1.0 referent & 0.50 & 462 \\
\hline
\end{tabular}

ORs and 95\% CIs were calculated using binary logistic regression. Data are shown as $\mathrm{n}$ and OR (95\% CI). Model A: adjustment for age and sex. Model B: age, sex, and cardiovascular risk factors (BMI, hypertension, LDL, smoking, and diabetes). Model C: age, sex, cardiovascular risk factors, and stroke severity. Model D: age, sex, cardiovascular risk factors, stroke severity, and hsCRP. LDL, low-density lipoprotein; BMI, body mass index; hsCRP, high-sensitivity C-reactive protein.

S-IGF-II quintiles after 3 months were not associated with functional outcome after 3 months or 2 years (data not shown).

\section{Discussion}

Previously, serum IGF-I and insulin resistance have been associated with IS outcome [32,40-42]. Here, we investigated the importance of IGF-II, which is more abundant in serum than IGF-I in adult life [1,12]. We found that both in the acute phase and after 3 months, s-IGF-II levels were modestly higher in IS cases than in the controls. The lowest quintile of acute s-IGF-II was associated with increased mortality also after full adjustment for covariates. In contrast, the associations between low acute s-IGF-II and poor functional outcome after 3 months and 2 years were not retained after full adjustments for covariates.

\subsection{IGF-II Levels in Normal Subjects and Stroke Patients}

The role of IGF-II in fetal life is well established, but there is a paucity of IGF-II studies in adult human life. There are a few studies that have reported that s-IGF-II slowly declined with increasing age in healthy male subjects [43]. Additionally, among healthy elderly subjects ( $\geq 60$ years), s-IGF-II tended to be lower in men compared to women [44]. Here, we confirm that s-IGF-II is inversely associated with age in healthy subjects, and that s-IGF-II is lower in men than in women. We extend the previous knowledge by showing that also in subjects with IS, there is a negative association between s-IGF-II and age as well as a sex difference in s-IGF-II. We also found modestly elevated s-IGF-II levels in IS cases, both in the acute phase (3.2\% higher than in controls) and after 3 months (3.5\%). In a study by Johnsen et al., investigating IGF and the risk of IS, s-IGF-II was non-statistically significantly inversely associated with the risk of IS [28]. However, as our study is the first one investigating acute s-IGF-II levels in human stroke, our results must be considered as preliminary observations until confirmed in other IS cohorts. Regarding etiological subtypes, we observed a pronounced reduction in s-IGF-II in cardioembolic stroke compared with the controls $(6.2 \%)$ and compared with the other stroke subtypes. For the other stroke subtypes, we observed higher s-IGF-II levels in cases compared to controls, although this difference was significant only in cryptogenic stroke $(7.3 \%)$. The finding of lower s-IGF-II levels in cardioembolic stroke needs replication and putative mechanisms remain to be elucidated. However, IS by cardioembolic etiology partly represents another type of pathophysiology, being derived by thrombosis mainly from atrial fibrillation and cardiac arrhythmias [45], as also suggested by the proposed roles of IGF-II in cardiac epigenetics in humans [46]. Finally, the lower level of s-IGF-II in cardioembolic stroke 
abided after stratifying for stroke severity and CRP (data not shown), as well as remaining significant after 3 months, which argues against the notion that this finding merely reflects an acute stress response.

\subsection{IGF-II and Mortality}

The lowest quintile of acute s-IGF-II was associated with an increased risk of mortality compared to that in the four higher quintiles after adjustment for covariates. Previously, the association between s-IGF-II and mortality had not been investigated in stroke patients, and data from other study populations were limited. However, recent human research suggests that IGF-II is associated with cardiovascular risk factors. Results from genetic studies imply that the IGF-II genomic region may be involved in metabolic syndrome, type 2 diabetes, coronary heart disease, and mortality [22,23,47-50]. Interestingly, studies of the APAI polymorphism of the IGF2 gene have demonstrated that the APAI A allele is associated with higher serum IGF-II levels and less obesity $[16,20,21]$. This allele was also positively associated with longevity in the Jerusalem longitudinal study, although the actual s-IGF-II levels were not presented [22]. Moreover, a decline in s-IGF-II in mid-life was associated with subsequent weight gain [38]. Furthermore, s-IGF-II in children [51] as well as in adults [52] has been negatively associated with metabolic syndrome, and IGF-II is also dysregulated in diabetic nephropathy [53]. Hence, IGF-II might participate in the regulation of obesity and metabolic syndrome, thereby indirectly being a biomarker for cerebrovascular diseases [54]. In the present study, we investigated whether s-IGF-II correlated with metabolic factors and found a modest positive relationship between acute s-IGF-II and LDL, but there was no correlation with insulin resistance as indexed by HOMAIR. In addition, the association between low acute s-IGF-II and increased mortality was independent from cardiovascular risk factors as the association also remained significant after adjustment for these factors. Finally, low 3-month s-IGF-II was not associated with increased mortality, which further refutes that long-term effects on cardiometabolic factors were of major importance.

IGF-II is positively correlated with the risk of malignancy as well as cancer mortality [55], and IGF-II is overexpressed in cancers of different origins [56-58]. Overall, it is therefore unlikely that the association between low acute s-IGF-II and increased mortality in our study can be explained by an increased risk of cancer mortality.

We found an inverse correlation between acute s-IGF-II and hsCRP, suggesting a link between low s-IGF-II and systemic inflammation in the acute phase of IS. However, the significance of such interactions is uncertain as the association between the lowest quintile of acute s-IGF-II and increased risk of mortality remained after inclusion of hsCRP and stroke severity as covariates. Furthermore, in experimental IS, IGF-II was involved in inflammatory responses in activated macrophage IS [25] and provided protection from experimentally induced oxidative damage [16-18]. In humans, rh-IGF-II is available for research studies, but no experimental study has been carried out in the context of IS, and rhIGF-II is not available for clinical usage. Therefore, effects of IGF-II on local inflammatory responses or oxidative stress could theoretically have been of importance. However, we cannot rule out that there are unknown confounders that we did not adjust for. Therefore, in summary, the underlying mechanisms are unclear and need to be clarified in further studies including whether IGF-II could exert direct, yet unidentified effects.

\subsection{Modulation of IGF-II Activity}

Although s-IGF-II mainly originates from the liver [3], there is also some production in other tissues including the CNS, most prominently in neurons [4,5]. Furthermore, IGFII can pass through the blood-brain barrier [6] and potentially activate both the IGF-I receptor (IGF1R) with low affinity and the IGF-II receptor (IGF2R) with high affinity. Both are widely distributed in the brain $[4,5]$. Together with the six high-affinity IGF-binding proteins (IGFBPs), they are likely involved in a complex regulation of the effects of IGFII, but to our knowledge, modulating these in terms of IGF-II signaling has not been 
performed. Further studies focusing on the regulation and mechanisms of how IGF-II exerts its effect in stroke may therefore benefit from measuring the actual levels of IGF-II as well as the IGFBPs in the serum as well as in the CNS.

Interestingly, there are other alternatives of modulating IGF-II activity, namely, by the so-called IGF2 mRNA binding proteins (IMPs). These exist as several subtypes and are expressed in multiple tissues including the brain, playing a major role in post-transcriptional regulation of RNAs, providing an opportunity to modulate IGF-II activity [27,59]. In adulthood, only the subtype IMP2 remains relatively highly expressed, and in genetic studies, IMP2 has been implicated in the regulation of metabolism, development, stemness, and tumorigenesis [59] and diabetes [48]. In the subgranular zone of the adult rodent dentate gyrus, the small protein RNA-binding motif protein 3 (RBM3) promoted IGF-II expression and secretion by interacting with IMP2, thereby providing neuroprotection and neurogenesis after hypoxic-ischemic brain injury [27]. It is possible to produce small compounds that stabilize RBM3, and successful, although not fully validated, attempts have been performed using a cold-inducible RNA-binding protein (CIRBP) homologue [60]. Therefore, there is a possibility that in the future, IGF-II activity could be modulated in brain disorders including stroke by targeting the IMP2-IGF-II pathway.

\subsection{IGF-II and Functional Outcome}

There was an association between the lowest quintile of acute s-IGF-II and increased risk of poor functional outcome after 3 months and 2 years, which could be in line with adverse consequences of low IGF-II in acute IS. The risk of poor functional outcome was highest after 3 months, just over 2-fold. This excess risk of poor functional outcome remained when mRS 6, i.e., dead, was left out of the analysis (data not shown), hinting that this association was not merely an effect driven by an excess mortality. However, the association between the lowest quintile of acute s-IGF-II and poor functional outcome lost statistical significance after full adjustment for covariates including stroke severity and hsCRP. Comparatively, the association between the lowest quintile and risk of mortality was more robust and also withstood our most extensive multivariate analysis in this study. This implicates that the association between s-IGF-II and functional outcome may be related to cardiovascular risk factors rather than a mechanism of neuroprotection and recovery after IS. Thus, IGF-II could be an effector rather than a primary mediator in terms of long-term functional outcome after IS.

\subsection{Strengths and Limitations}

In the context of analyzing levels of s-IGF-II, our study had a relatively large study sample including consecutive and well-characterized IS cases and population-based controls. In terms of the multivariate regression models for functional outcome and mortality, statistical power was retained with reasonable strength with the adjustment for several, but not an unlimited number of, potential confounders [61]. Although low s-IGF-II may be a pre-stroke risk marker for ischemic stroke, as shown in a primary prevention perspective [28], our analysis was confined to mortality and functional outcome from a secondary prevention perspective. We included Caucasian IS cases and controls that were below 70 years of age, which limits the generalizability of the results from a global perspective $[43,62]$. An advantage of our study is that the blood samples were taken twice, both in the acute phase and after 3 months. A limitation is that the acute blood samples were usually not drawn immediately after stroke onset; i.e., they were taken after a median of 4 days, hence, to some extent, reflecting the stress response in the acute phase of IS. Finally, the levels of s-IGF-II in stroke subtypes must be interpreted with caution as the number of cases in these subgroups was limited $(\mathrm{N}=54-131)$. 


\section{Conclusions}

Our study shows that s-IGF-II is elevated both in the acute phase and 3 months after IS. Low acute s-IGF-II was independently associated with an increased risk of mortality after IS, whereas the associations with functional outcome lost significance after adjustment for covariates. However, as our study is the first one of s-IGF-II in human stroke, our results need to be confirmed in other IS cohorts.

Author Contributions: Conceptualization, D.Å., N.D.Å., K.J., J.I., C.J. and J.S.; methodology, K.J., P.R., C.B. and C.J.; formal analysis, D.Å. and J.S.; investigation, D.Å., N.D.Å., K.J., P.R. and J.S.; writing-original draft preparation, D.A. and J.S.; writing-review and editing, D.Å., N.D.Å., K.J., P.R., C.B., J.I., C.J. and J.S.; visualization, D.Å., N.D.Å. and J.S.; funding acquisition, N.D.Å., C.B., C.J., J.I. and J.S. All authors have read and agreed to the published version of the manuscript.

Funding: This study was supported by the Swedish state under the agreement between the Swedish government and the county councils, the ALF-agreement (ALFGBG-720081, ALFGBG-722371, ALFGBG719761), the Swedish Medical Society (Svenska Läkaresällskapet), the Swedish Research Council (2018-02543), the Swedish Heart Lung Foundation (20190203), the Swedish Stroke Association, the Göteborg Foundation for Neurological Research, the Rune and Ulla Amlöv, Edit Jacobson, Magnus Bergvall, Emelle, Lars Hierta, and John and Brit Wennerström foundations.

Institutional Review Board Statement: This study was conducted in accordance with the 1964 Helsinki Declaration and its later amendments or comparable ethical standards. This study was approved by the Ethics Committee of the University of Gothenburg (Ö469-99 and T553-03). The Ethics Committee of the University of Gothenburg is responsible for ethical applications from the entire region of western Sweden, covering all four hospitals in the study.

Informed Consent Statement: All participants or next of kin provided written informed consent.

Data Availability Statement: The data presented in this study are available on reasonable request from the corresponding author. The data are not publicly available due to legal restrictions regarding privacy and ethical issues.

Acknowledgments: The authors thank research nurse Ingrid Eriksson for her excellent work and assistance with the study patients and controls.

Conflicts of Interest: The authors declare that they have no competing interests.

\section{References}

1. Le Roith, D.; Butler, A.A. Insulin-like Growth Factors in Pediatric Health and Disease. J. Clin. Endocrinol. Metab. 1999, 84, 4355-4361. [CrossRef] [PubMed]

2. Benarroch, E.E. Insulin-like growth factors in the brain and their potential clinical implications. Neurology 2012, 79, $2148-2153$. [CrossRef] [PubMed]

3. Adamek, A.; Kasprzak, A. Insulin-Like Growth Factor (IGF) System in Liver Diseases. Int. J. Mol. Sci. 2018, 19, 1308. [CrossRef] [PubMed]

4. Ohlsson, C.; Mohan, S.; Sjögren, K.; Tivesten, A.; Isgaard, J.; Isaksson, O.; Jansson, J.-O.; Svensson, J. The Role of Liver-Derived Insulin-Like Growth Factor-I. Endocr. Rev. 2009, 30, 494-535. [CrossRef] [PubMed]

5. Rivera, E.J.; Goldin, A.; Fulmer, N.; Tavares, R.; Wands, J.R.; De La Monte, S.M. Insulin and insulin-like growth factor expression and function deteriorate with progression of Alzheimer's disease: Link to brain reductions in acetylcholine. J. Alzheimer's Dis. 2005, 8, 247-268. [CrossRef]

6. Reinhardt, R.R.; A Bondy, C. Insulin-like growth factors cross the blood-brain barrier. Endocrinology 1994, 135, $1753-1761$. [CrossRef]

7. Russo, V.C.; Gluckman, P.D.; Feldman, E.L.; Werther, G.A. The Insulin-Like Growth Factor System and Its Pleiotropic Functions in Brain. Endocr. Rev. 2005, 26, 916-943. [CrossRef] [PubMed]

8. Fernandez, A.M.; Torres-Alemán, I. The many faces of insulin-like peptide signalling in the brain. Nat. Rev. Neurosci. 2012, 13, 225-239. [CrossRef] [PubMed]

9. Hawkes, C.; Kar, S. The insulin-like growth factor-II/mannose-6-phosphate receptor: Structure, distribution and function in the central nervous system. Brain Res. Rev. 2004, 44, 117-140. [CrossRef] [PubMed]

10. Hawkes, C.; Jhamandas, J.H.; Harris, K.H.; Fu, W.; Macdonald, R.G.; Kar, S. Single Transmembrane Domain Insulin-Like Growth Factor-II/Mannose-6-Phosphate Receptor Regulates Central Cholinergic Function by Activating a G-Protein-Sensitive, Protein Kinase C-Dependent Pathway. J. Neurosci. 2006, 26, 585-596. [CrossRef] 
11. Masunaga, Y.; Inoue, T.; Yamoto, K.; Fujisawa, Y.; Sato, Y.; Kawashima-Sonoyama, Y.; Morisada, N.; Iijima, K.; Ohata, Y.; Namba, N.; et al. IGF2 Mutations. J. Clin. Endocrinol. Metab. 2019, 105, 116-125. [CrossRef] [PubMed]

12. Hertze, J.; Nägga, K.; Minthon, L.; Hansson, O. Changes in cerebrospinal fluid and blood plasma levels of IGF-II and its binding proteins in Alzheimer's disease: An observational study. BMC Neurol. 2014, 14, 64. [CrossRef] [PubMed]

13. Chen, D.Y.; Stern, S.A.; Garcia-Osta, A.; Saunier-Rebori, B.; Pollonini, G.; Bambah-Mukku, D.; Blitzer, R.D.; Alberini, C.M. A critical role for IGF-II in memory consolidation and enhancement. Nat. Cell Biol. 2011, 469, 491-497. [CrossRef]

14. Shahmoradi, A.; Radyushkin, K.; Rossner, M.J. Enhanced memory consolidation in mice lacking the circadian modulators Sharp1 and -2 caused by elevated Igf2 signaling in the cortex. Proc. Natl. Acad. Sci. USA 2015, 112, E3582-E3589. [CrossRef] [PubMed]

15. Steinmetz, A.B.; Johnson, S.A.; Iannitelli, D.E.; Pollonini, G.; Alberini, C.M. Insulin-like growth factor 2 rescues aging-related memory loss in rats. Neurobiol. Aging 2016, 44, 9-21. [CrossRef]

16. Castilla-Cortázar, I.; García-Fernández, M.; Delgado, G.; E Puche, J.; Sierra, I.; Barhoum, R.; González-Barón, S. Hepatoprotection and neuroprotection induced by low doses of IGF-II in aging rats. J. Transl. Med. 2011, 9, 103. [CrossRef]

17. Montañez, E.M.; Pavia, J.; Santin, L.J.; Boraldi, F.; Estivill-Torrus, G.; Aguirre, J.A.; Garcia-Fernandez, M. Involvement of IGF-II receptors in the antioxidant and neuroprotective effects of IGF-II on adult cortical neuronal cultures. Biochim. Biophys. Acta Mol. Basis Dis. 2014, 1842, 1041-1051. [CrossRef]

18. Montañez, E.M.; Millon, C.; Boraldi, F.; Garcia-Guirado, F.; Pedraza, C.; Lara, E.; Santin, L.; Pavia, J.; Garcia-Fernandez, M. IGF-II promotes neuroprotection and neuroplasticity recovery in a long-lasting model of oxidative damage induced by glucocorticoids. Redox Biol. 2017, 13, 69-81. [CrossRef]

19. Lee, D.-H.; Singh, P.; Tsark, W.M.K.; Szabó, P.E. Complete Biallelic Insulation at the H19/Igf2 Imprinting Control Region Position Results in Fetal Growth Retardation and Perinatal Lethality. PLoS ONE 2010, 5, e12630. [CrossRef]

20. O'Dell, S.; Miller, G.; Cooper, J.; Hindmarsh, P.; Pringle, P.; Ford, H.; Humphries, S.; Day, I. Apal polymorphism in insulin-like growth factor II (IGF2) gene and weight in middle-aged males. Int. J. Obes. 1997, 21, 822-825. [CrossRef] [PubMed]

21. O'Dell, S.D.; Day, I.N. Molecules in focus Insulin-like growth factor II (IGF-II). Int. J. Biochem. Cell Biol. 1998, 30, 767-771. [CrossRef]

22. Stessman, J.; Maaravi, Y.; Hammerman-Rozenberg, R.; Cohen, A.; Nemanov, L.; Gritsenko, I.; Gruberman, N.; Ebstein, R.P. Candidate genes associated with ageing and life expectancy in the Jerusalem longitudinal study. Mech. Ageing Dev. 2005, 126, 333-339. [CrossRef] [PubMed]

23. De Luca, M.; Rose, G.; Bonafè, M.; Garasto, S.; Greco, V.; Weir, B.; Franceschi, C.; De Benedictis, G. Sex-specific longevity associations defined by Tyrosine Hydroxylase-Insulin-Insulin Growth Factor 2 haplotypes on the 11p15.5 chromosomal region. Exp. Gerontol. 2001, 36, 1663-1671. [CrossRef]

24. Beilharz, E.J.; Bassett, N.S.; Sirimanne, E.S.; Williams, C.E.; Gluckman, P.D. Insulin-like growth factor II is induced during wound repair following hypoxic-ischemic injury in the developing rat brain. Mol. Brain Res. 1995, 29, 81-91. [CrossRef]

25. Lee, W.-H.; Clemens, J.A.; Bondy, C.A. Insulin-like growth factors in the response to cerebral ischemia. Mol. Cell. Neurosci. 1992, 3 , 36-43. [CrossRef]

26. Stephenson, D.T.; Rash, K.; Clemens, J.A. Increase in Insulin-like Growth Factor II Receptor within Ischemic Neurons following Focal Cerebral Infarction. Br. J. Pharmacol. 1995, 15, 1022-1031. [CrossRef] [PubMed]

27. Zhu, X.; Yan, J.; Bregere, C.; Zelmer, A.; Goerne, T.; Kapfhammer, J.P.; Guzman, R.; Wellmann, S. RBM3 promotes neurogenesis in a niche-dependent manner via IMP2-IGF2 signaling pathway after hypoxic-ischemic brain injury. Nat. Commun. 2019, 10, 3983. [CrossRef]

28. Johnsen, S.P.; Hundborg, H.H.; Sørensen, H.T.; Ørskov, H.; Tjonneland, A.; Overvad, K.; Jørgensen, J.O.L. Insulin-Like Growth Factor (IGF) I, -II, and IGF Binding Protein-3 and Risk of Ischemic Stroke. J. Clin. Endocrinol. Metab. 2005, 90, 5937-5941. [CrossRef]

29. Åberg, D.; Johansson, P.; Isgaard, J.; Wallin, A.; Johansson, J.-O.; Andreasson, U.; Blennow, K.; Zetterberg, H.; Åberg, N.D.; Svensson, J. Increased Cerebrospinal Fluid Level of Insulin-like Growth Factor-II in Male Patients with Alzheimer's Disease. J. Alzheimer's Dis. 2015, 48, 637-646. [CrossRef]

30. Tham, A.; Nordberg, A.; Grissom, F.E.; Carlsson-Skwirut, C.; Viitanen, M.; Sara, V.R. Insulin-like growth factors and insulin-like growth factor binding proteins in cerebrospinal fluid and serum of patients with dementia of the Alzheimer type. J. Neural Transm. 1993, 5, 165-176. [CrossRef]

31. Jood, K.; Ladenvall, C.; Rosengren, A.; Blomstrand, C.; Jern, C. Family History in Ischemic Stroke before 70 Years of Age. Stroke 2005, 36, 1383-1387. [CrossRef]

32. Åberg, D.; Jood, K.; Blomstrand, C.; Jern, C.; Nilsson, M.; Isgaard, J.; Åberg, N.D. Serum IGF-I Levels Correlate to Improvement of Functional Outcome after Ischemic Stroke. J. Clin. Endocrinol. Metab. 2011, 96, E1055-E1064. [CrossRef]

33. Åberg, D.; Åberg, N.D.; Jood, K.; Holmegaard, L.; Redfors, P.; Blomstrand, C.; Isgaard, J.; Jern, C.; Svensson, J. Homeostasis model assessment of insulin resistance and outcome of ischemic stroke in non-diabetic patients-A prospective observational study. BMC Neurol. 2019, 19, 177. [CrossRef]

34. Åberg, N.D.; Åberg, D.; Jood, K.; Nilsson, M.; Blomstrand, C.; Kuhn, H.G.; Svensson, J.; Jern, C.; Isgaard, J. Altered levels of circulating insulin-like growth factor I (IGF-I) following ischemic stroke are associated with outcome-A prospective observational study. BMC Neurol. 2018, 18, 106. [CrossRef] [PubMed] 
35. Åberg, N.D.; Åberg, D.; Lagging, C.; Holmegaard, L.; Redfors, P.; Jood, K.; Nilsson, M.; Aberg, M.; Blomstrand, C.; Svensson, J.; et al. Association Between Levels of Serum Insulin-like Growth Factor I and Functional Recovery, Mortality, and Recurrent Stroke at a 7-year Follow-up. Exp. Clin. Endocrinol. Diabetes 2019, 128, 303-310. [CrossRef]

36. Watts, E.L.; Perez-Cornago, A.; Appleby, P.N.; Albanes, D.; Ardanaz, E.; Black, A.; Bueno-De-Mesquita, H.B.; Chan, J.M.; Chen, C.; Chubb, S.P.; et al. The associations of anthropometric, behavioural and sociodemographic factors with circulating concentrations of IGF-I, IGF-II, IGFBP-1, IGFBP-2 and IGFBP-3 in a pooled analysis of 16,024 men from 22 studies. Int. J. Cancer 2019, 145, 3244-3256. [CrossRef] [PubMed]

37. Ceda, G.P.; Dall'Aglio, E.; Magnacavallo, A.; Vargas, N.; Fontana, V.; Maggio, M.; Valenti, G.; Lee, P.D.K.; Hintz, R.L.; Hoffman, A.R. The Insulin-Like Growth Factor Axis and Plasma Lipid Levels in the Elderly1. J. Clin. Endocrinol. Metab. 1998, 83, 499-502. [CrossRef]

38. Zaina, S.; Pettersson, L.; Thomsen, A.B.; Chai, C.-M.; Qi, Z.; Thyberg, J.; Nilsson, J. Shortened Life Span, Bradycardia, and Hypotension in Mice with Targeted Expression of anIgf2Transgene in Smooth Muscle Cells. Endocrinology 2003, 144, $2695-2703$. [CrossRef]

39. Husted, C.I.; Valencik, M. Insulin-like growth factors and their potential role in cardiac epigenetics. J. Cell. Mol. Med. 2016, 20, 1589-1602. [CrossRef] [PubMed]

40. Rodríguez, S.; Gaunt, T.R.; O’Dell, S.D.; Chen, X.-H.; Gu, N.; Hawe, E.; Miller, G.J.; Humphries, S.E.; Day, I.N. Haplotypic analyses of the IGF2-INS-TH gene cluster in relation to cardiovascular risk traits. Hum. Mol. Genet. 2004, 13, 715-725. [CrossRef] [PubMed]

41. Christiansen, J.; Kolte, A.M.; O Hansen, T.V.; Nielsen, F.C. IGF2 mRNA-binding protein 2: Biological function and putative role in type 2 diabetes. J. Mol. Endocrinol. 2009, 43, 187-195. [CrossRef]

42. Ng, M.C.Y.; Shriner, D.; Chen, B.H.; Li, M.; Chen, W.-M.; Guo, X.; Liu, J.; Bielinski, S.J.; Yanek, L.R.; Nalls, M.A.; et al. MetaAnalysis of Genome-Wide Association Studies in African Americans Provides Insights into the Genetic Architecture of Type 2 Diabetes. PLoS Genet. 2014, 10, e1004517. [CrossRef]

43. Mercader, J.M.; Liao, R.G.; Bell, A.D.; Dymek, Z.; Estrada, K.; Tukiainen, T.; Huerta-Chagoya, A.; Moreno-Macías, H.; Jablonski, K.A.; Hanson, R.L.; et al. A Loss-of-Function Splice Acceptor Variant in IGF2 Is Protective for Type 2 Diabetes. Diabetes 2017, 66, 2903-2914. [CrossRef]

44. Sandhu, M.S.; Gibson, J.M.; Heald, A.H.; Dunger, D.B.; Wareham, N.J. Low Circulating IGF-II Concentrations Predict Weight Gain and Obesity in Humans. Diabetes 2003, 52, 1403-1408. [CrossRef]

45. Inzaghi, E.; Ferroli, B.B.; Fintini, D.; Grossi, A.; Nobili, V.; Cianfarani, S. Insulin-Like Growth Factors and Metabolic Syndrome in Obese Children. Horm. Res. Paediatr. 2017, 87, 400-404. [CrossRef] [PubMed]

46. Pouriamehr, S.; Barmaki, H.; Rastegary, M.; Lotfi, F.; Afjadi, M.N. Investigation of insulin-like growth factors/insulin-like growth factor binding proteins regulation in metabolic syndrome patients. BMC Res. Notes 2019, 12, 653. [CrossRef]

47. Hjortebjerg, R.; Tarnow, L.; Jorsal, A.; Parving, H.-H.; Rossing, P.; Bjerre, M.; Frystyk, J. IGFBP-4 Fragments as Markers of Cardiovascular Mortality in Type 1 Diabetes Patients with and without Nephropathy. J. Clin. Endocrinol. Metab. 2015, 100, 3032-3040. [CrossRef]

48. Holly, J.M.P.; Biernacka, K.; Perks, C.M. The Neglected Insulin: IGF-II, a Metabolic Regulator with Implications for Diabetes, Obesity, and Cancer. Cells 2019, 8, 1207. [CrossRef] [PubMed]

49. Gallagher, E.J.; Leroith, D. Minireview: IGF, Insulin, and Cancer. Endocrinology 2011, 152, 2546-2551. [CrossRef]

50. Murphy, S.K.; Huang, Z.; Wen, Y.; Spillman, M.A.; Whitaker, R.S.; Simel, L.R.; Nichols, T.D.; Marks, J.R.; Berchuck, A. Frequent IGF2/H19 Domain Epigenetic Alterations and Elevated IGF2 Expression in Epithelial Ovarian Cancer. Mol. Cancer Res. 2006, 4, 283-292. [CrossRef] [PubMed]

51. Zhao, R.; DeCoteau, J.F.; Geyer, C.; Gao, M.; Cui, H.; Casson, A.G. Loss of imprinting of the insulin-like growth factor II (IGF2) gene in esophageal normal and adenocarcinoma tissues. Carcinogenesis 2009, 30, 2117-2122. [CrossRef] [PubMed]

52. Liou, J.-M.; Shun, C.-T.; Liang, J.-T.; Chiu, H.-M.; Chen, M.-J.; Chen, C.; Wang, H.-P.; Wu, M.-S.; Lin, J.-T. Plasma Insulin-Like Growth Factor-Binding Protein-2 Levels as Diagnostic and Prognostic Biomarker of Colorectal Cancer. J. Clin. Endocrinol. Metab. 2010, 95, 1717-1725. [CrossRef]

53. Dai, N. The Diverse Functions of IMP2/IGF2BP2 in Metabolism. Trends Endocrinol. Metab. 2020, 31, 670-679. [CrossRef]

54. Coderch, C.; de Cerio, M.D.; Zapico, J.M.; Peláez, R.; Larrayoz, I.M.; Ramos, A.; Martínez, A.; de Pascual-Teresa, B. In silico identification and in vivo characterization of small molecule therapeutic hypothermia mimetics. Bioorg. Med. Chem. 2017, 25, 6597-6604. [CrossRef]

55. Peduzzi, P.; Concato, J.; Kemper, E.; Holford, T.R.; Feinstein, A.R. A simulation study of the number of events per variable in logistic regression analysis. J. Clin. Epidemiol. 1996, 49, 1373-1379. [CrossRef]

56. Heald, A.H.; Anderson, S.G.; Ivison, F.; Laing, I.; Gibson, J.M.; Cruickshank, K. C-reactive protein and the insulin-like growth factor (IGF)-system in relation to risk of cardiovascular disease in different ethnic groups. Atherosclerosis 2003, 170, 79-86. [CrossRef]

57. Ali, K.; Cheek, E.; Sills, S.; Crome, P.; Roffe, C. Development of a Conversion Factor to Facilitate Comparison of National Institute of Health Stroke Scale Scores with Scandinavian Stroke Scale Scores. Cerebrovasc. Dis. 2007, 24, 509-515. [CrossRef] [PubMed]

58. Gray, L.J.; Ali, M.; Lyden, P.D.; Bath, P.M. Interconversion of the National Institutes of Health Stroke Scale and Scandinavian Stroke Scale in Acute Stroke. J. Stroke Cerebrovasc. Dis. 2009, 18, 466-468. [CrossRef] 
59. Adams, H.P.; Bendixen, B.H.; Kappelle, L.J.; Biller, J.; Love, B.B.; Gordon, D.L.; E Marsh, E. Classification of subtype of acute ischemic stroke. Definitions for use in a multicenter clinical trial. TOAST. Trial of Org 10172 in Acute Stroke Treatment. Stroke 1993, 24, 35-41. [CrossRef]

60. Matthews, D.R.; Hosker, J.P.; Rudenski, A.S.; Naylor, B.A.; Treacher, D.F.; Turner, R.C. Homeostasis model assessment: Insulin resistance and $\beta$-cell function from fasting plasma glucose and insulin concentrations in man. Diabetologia 1985, 28, 412-419. [CrossRef] [PubMed]

61. Ladenvall, C.; Jood, K.; Blomstrand, C.; Nilsson, S.; Jern, C.; Ladenvall, P. Serum C-Reactive Protein Concentration and Genotype in Relation to Ischemic Stroke Subtype. Stroke 2006, 37, 2018-2023. [CrossRef] [PubMed]

62. Bondanelli, M.; Ambrosio, M.R.; Zatelli, M.C.; Basaglia, N.; Degli Uberti, E.C. Prevalence of hypopituitarism in patients with cerebrovascular diseases. J. Endocrinol. Investig. 2008, 31, 16-20. 